\title{
Character's Exclusion and Inclusion Representations in Sinan Antoon's 'The Corpse Washer'
}

\author{
Asst. Prof. Dr. Raed Dakhil Kareem \\ M.A. Researcher Ali Mohammad Ridha Smesim, IRAQ - University of Kufa
}

\begin{abstract}
The current study is an attempt to demonstrate how characters are represented in Sinan Antoon's Self-translated novel 'The Corpse Washer'. The study adopts a Critical Discourse Analysis framework to analyse major characters' utterances through the use of van Leeuwen's socio-semantic Model 'Social Actor Representation'. The linguistic analysis of characters' utterances aims at analysing the active and passive representation within the novel as well as the character's importance by tracking the frequency of representation. The main aim of this study is to check the applicability of Social actor representation to literary social actors within novels since previous studies used this model to analyse non-fictional social actors. The result shows that the characters are included more than excluded and activated more than passivated due to the characters of the novel. Moreover, the chosen model for this study shows its effectiveness in analysing the selected data.
\end{abstract}

Keywords:

Critical discourse analysis, Van Leeuwen, social actor representation, Sinan Antoon, The Corpse Washer

Article Received: 18 October 2020, Revised: 3 November 2020, Accepted: 24 December 2020

\section{Introduction}

Discourse analysis is major field in linguistics since it was first introduced by Zeling Harris in 1952 (Paltridge 2012:2). The way of using the term 'discourse analysis' had changed as it is nowadays well-built field within linguistics (Fairclough 1993:134). Discourse analysis is defined in terms of two paradigms: structure and function. The structure paradigm is concerned with analysing the form of the language, while the functional one is interested in language use (Shiffrin 1994:340).

Foucault and Sheridan (1972:79) introduce a different perspective of 'discourse' as they point out to the concept of knowledge or 'episteme'. They believe that 'discourse' is not a piece of text, but a "practice that systematically form the objects of which they speak". For Foucault (in Hall 1992:291), 'discourse' means “a group of statements which provide a language for talking about a particular topic at a particular historical moment". Foucault argues that what constructs and governs a topic to be meaningful is discourse. Furthermore, discourse also affects how ideas are put into practice and can regulate the interpretation of others. This indicates that discourse exercises limitations and restrictions on the ways of talking and producing knowledge about it.

Many scholars (van Dijk 1988:108; Fairclough and Wodak 1997:258-284) regard discourse as a social practice, stressing on the importance of context of language use. Wodak and Meyer (2009:5) emphasize the importance of the context of the language use, drawing upon Bernstein's (1990) 'recontextualization' in which the term 'discourse' is based on the recontextualising principle which selectively recollects, appropriates, refocuses and relates different discourses with each other in a specific order.

It is worth mentioning, that the 'discourse' and 'text' are used differently by linguists and researchers. The term 'text' refers to a communicative action which should show the criteria: cohesion; coherence; intentionality; acceptability; informativity; situationality; intertextuality (Beaugrande and Dressler 1981). The other term, 'discourse', according to Van Leeuwen (2008:6), is "a socially constructed 
knowledge" developed in particular contexts and bound to them which could be large as in 'multinational corporations' or could be small as family conversation. Consequently, since discourse is a social cognition, there are specific social ways of interpreting social practices which are considered as important resources for representing social practices in a text. Moreover, discourse can include texts with other criteria that help to convey meaning such as (images, videos, voices, and others).

One of the main objectives of CDA is that it focuses on concepts as power and ideology to investigate the formation of ideologies through linguistic mechanisms to construct social ideas that shape social actions. Through the use of these tools, Van Leeuwen (2008) forms an approach that aims at examining the ways of realizing the character of each action through a linguistic manner which can pare the way to uncover potential underlying ideologies. This representation can show the character's (social actor) views, attitudes and ideologies through a qualitative and quotative tools.

\section{CDA and Fiction}

Discourse analysis in linguistics usually investigates non-fictional texts, claiming that fictional texts are mostly landed in stylistics. It is unusual for CDA to treat fiction as a suitable epistemological site (Sunderland, 2004:142). In other words, CDA tends to analyse static, direct and explicit type of discourse as linguistically and objectively as possible. Yet, fiction is typically dynamic, manipulative and complex where different aspects (like: time, place, the reader, the author, the characters, ...etc.) play a major role in the way of interpreting the meaning behind it.

According to Cook (1990) fiction and conversations can be named as 'discourse', so CDA with its approaches could be applied to fiction. Major theorists tried to apply CDA to fiction (Sunderland 2004; Stephens1992; Talbot 1995). Sunderland (2004:143) states that the fictional texts have their own complexities for linguistic analysis, among them is the 'aspect of point of view' where the narrator may not be the author or there may be several narrators. Sunderland states "any sentiment expressed by a character cannot be taken as indexing approval by the author" (2004:143). The second question for discourse analysis is the role of humour, irony and satire; they can be found in any text but they have major effects in fictional texts. The third issue is the aspect of fantasy which gives the author the ability to extend the character's practices outside the world of reality. The last and important problem of fiction is the multimodal nature of fiction where there are their different readings of the text as a totality and the relationship between different semiotic resources that construct the meaning.

In general, the linguistic analysis of discourse tends to study the direct, explicit and clear texts (spoken or written) such as (news, speeches, conversation). It faces some problems in investigating the fictional text due to its manipulative nature of using different tools of language like (different semiotic resources, indirect or hidden meaning). This will lead to the complex construction of different realities away from the real one.

\section{Social Actor Representation (SAR)}

SAR is developed by Van Leeuwen to identify the participants of SAs. The approach is interested in the actor of the social action rather than the social structure. It also draws up a socio-semantic inventory to the ways in which the SA is represented and establish a sociological and critical relevance of various categories. It stands upon two main assumptions: first: the lock of biuniqueness in the language that can be realized through the way of analyzing the agent, secondly is meaning is culturally based (Van Leeuwen 2008:23). SAR network analyzes social actor (henceforth SA) according to a number of categories, but due to the paper limitation this paper focus on activation and passivation applied in "The Corpse Washer". 


\subsection{Exclusion}

The SA may not be present in the text all of the time. The exclusion of SA can sometimes occur to suit the interests of the reader and the intentions of the speaker or writer. Specifically, exclusion is used when the speaker or writer excludes the actors that play roles in the action within the discourse. This omission is one of the techniques of deletion which may be 'innocent' due to the speaker's assumption that readers possess the knowledge about the actor (Van Leeuwen 2008:28). Exclusion has two types: suppression and backgrounding. The main difference between the two types lies in the point of leaving a trace or not in the discourse.

\subsubsection{Suppression}

The radical exclusion of the SA along with its activities is called 'suppression'. This type of omission leaves no trace or any reference to the actor within discourse. Van Leeuwen states that suppression can be realized linguistically through 'passive agent deletion' (Van Leeuwen 2008:29) as in:

- In Japan similar concerns are being expressed about a mere trickle of Third World immigrants.

The previous example shows the transformation of the sentence to passive voice and the deletion of the SA which causes suppression. This kind of deletion is sometimes used to neglect the doer of the action, paying more attention to the action itself or the results. The other realization of suppression is the use of non-finite clauses that function as a grammatical participant as in:

- To maintain this policy is hard.

Furthermore, the third realization of suppression is through using nominalization and process nouns which is similar to a certain extent, to passive agent deletion in which the doer of the action is replaced by a noun phrase that represents him/her as in:

- The level of support for stopping immigration altogether was at a post-war high.
The example demonstrates the replacement of the SA with an alternative one that takes his role but does not declare it.

\subsubsection{Backgrounding}

It means the exclusion that leaves traces for the SA to be mentioned elsewhere in another part of the clause in the same sentence or in another part of the text. It can be realized through different techniques such as (Van Leeuwen 2008: 30):

A- Infinite clause-ing: Using this technique can delay the mention of the SA to another part of the sentences. The sentence in this case will start by a clause.

B- The use of paratactic clauses: This type of clauses allows the author to delete the SA; yet, mentioning it would be in another clause in the sentence.

C- Infinitival clause-to: This technique is the same as "infinitival clause-ing" which functions as an introduction to the next clause which includes the SA.

Van Leeuwen (2008:31) argues that it is hard sometimes to know if the suppressed SA is retrievable by the reader (through past experience) or by the writer (through mentioning it in another place in the text). Sometimes, the deletion can be for the reasons of over communication. Yet, this deletion might block the access to the knowledge of the practice.

\subsection{Inclusion}

This strategy is the opposite to exclusion in the way that the SA is clear and is mentioned its position in the sentence. Inclusion is divided into several subcategories based on the different representations of the SA by the speaker (Van Leeuwen, 2008:32).

\subsubsection{Activation and Passivation}

SAR may be found as an active dynamic force in an activity which is called activation.

Activation is linguistically realized through five different ways (Van Leeuwen 2008:33):

A- The grammatical representation of the participant especially the SA in the sentence.

B- It can also be realized through circumsterilization. It happens when the SA is 
preceded by a prepositional phrase headed by "from.

C- Another way of realizing activation is through 'possessivation' by using possessive pronouns.

D- Using post modification can help realize the activation through the use of the noun after the preposition 'of'.

E- The last strategy of activation is by using premodification.

On the other hand, passivation is used to focus on actions rather actors. It occurs when the SA is represented as an 'undergoing' activity. Moreover, passivation is divided into two distinctions:

1- Subjection: the representation of SA as an object or beneficialzed, positively or negatively affected by the action or benefiting from it. Additionally, it is realized through four main ways (Van Leeuwen, 2008: 34):

A- The use of participation when the passive SA is a "goal process, phenomenal in the mental process or a carrier in an effective attributive process" (Halliday 1985, cited in Van Leeuwen 2008:34).

B- It can be realized through circumstantialization, by using a prepositional phrase, headed by 'for' or 'against' as in:

C- Subjection can also be realized through the use of 'possessivation' by using the prepositional phrase headed by "of" as a post modification to nominalization or a process noun as in:

D- Adjectival premodification can be also used by one of the realizations of subjection as in:

2- Beneficialization: it can be realized through participation, in which "the benficialized participants is recipient or client in relation to material process or receiver in relation to a verbal process" (Halliday 1985:132-33 cited in Van Leeuwen 2008:34).

\section{Review of Related Literature}

SAR is used in several studies in the field of linguistics: in various areas such as political discourse, gender representation, education books but most commonly in newspapers. The application of SAR to literary text is rare; it has been used only two times before.

Evayani and Rido (2019), in their study 'Representation of SAs in Sexual Violence Issue in the New York Times and The Jakarta Post Newspapers: A Critical Discourse Analysis', investigate the issue of sexual violence in newspaper articles, namely New York Times and Jakarta Post Newspapers. The researchers employ SAR framework to analyse the representation of victims and perpetrators in the articles discuses sexual violence actions. The findings of the study show that both newspapers use suppression and backgrounding strategy in their articles, and that both of them mostly represent victims in passive agents, while active agents are spaced for perpetrators. The researches point out that there is a salient difference between the two newspapers in terms of the inclusion strategy. Jakarta Post presents actors as individuals by mentioning their names, age and occupation, whereas New York Times tends to present them by their surname and their social status like "Mr., Dr., Prof., etc.".

Political discourse is one of the major fields that applies SAR to discover the representation of SA in various areas. Anwar's thesis (2018), entitled 'Social Actor Represented by President Donald Trump on Twitter', explores how Trump uses particular strategies in writing his opinion over critical issues. The researcher also argues that simple words and tweets can hold implicit and explicit ideas. The thesis is qualitative in nature, providing a deep analysis of data. The data analysis includes fourteen tweets posted in the period between January and April 2018. Anwar uses three-stage analysis: first, reading and understanding the intended meaning, then analysing the tweets through Van Leeuwen's framework and finally classifying the data for answering research questions. Anwar has concluded that Trump often uses inclusion strategy over exclusion. The analysis of the tweets leads to the result that the president of America 
uses his power to influence the citizens about his personal political perspective.

SAR is used in literature and/or translation by Babaii and Rashed (2017) in their paper that is entitled 'Representation of Social Actors in Chinua Achebe's novel Things Fall Apart and its two Persian Translations'. They have employed discourse-based approach to examine the representation of social-cultural context via translation. Two versions of translation to the above novel are selected to study their similarities and differences between the two translations in compare to the original text. They employed Van Leeuwen's (2008) SAR as the analytical framework to achieve the following aim: the investigation of the contribution of critical discourse analysis to the field of translation. The results show that there are several distortions between the source and target text in the micro lexico-grammatical levels. The researchers have also pointed out that this distortion could not be as significant as the damage to the overall ideological message of the source text. Furthermore, this distortion could be different in terms of the macro-cultural distance between the two texts.

Joodi (2018) in his thesis 'Characters as Social Constructs in G.B Shaw's Man and Superman' also has used Van Leeuwen's framework to investigate characters' different ideologies, perspectives and attitudes throughout one of Shaw's plays. The aim of this study is to investigate the applicability of the framework to the drama actors. The thesis has concluded that the characters frequently use the inclusion strategy than exclusion, and activation more than passivation with specific tendencies towards individualization, functionalization and identification.

\section{Statement of the Problem}

Through analyzing the data of "The Corpus Washer", the following problems are underscored: 1- The applicability of the framework to investigate the tri-factors is to be uncovered, hopefully leading to the representation of the SA in "The Corpus Washer" because of the lack of literary work studies which deal with this manner.

2- The nature of the novel results in a major problem as it is "first-person narration" which leads to the construction of one character's reality (Jawad) and all the other characters portrayed through the main character's interaction with them.

3- The nature of the literary work which has different characteristics more complex than the factual language.

\subsection{Limits of the Study}

1- This study mainly focuses on the linguistic aspect of the novel.

2- The analysis of the nightmares in the novel and its impact on the plot in the novel.

3- The study analyzes the main characters in the novel that have a major role in the plot.

4- Choosing the main character depends on the appearance of these characters in more than one chapter with his participation in the plot.

\subsection{Significance of the Study}

The current study employs the CDA tools for the significance of understanding social representation in literary works. The study draws attention to the applicability of Van Leeuwen's model of analysis (SAR), which is mainly used for political discourse, articles, interviews but rarely for literary works, especially novels. Thus, this is the point of creative extension of (SAR). In addition, Sinan Antoon's novels have not been studied from a linguistic perspective, especially a discourse framework. Therefore, this study bridges the gap between literature and critical discourse analysis.

\subsection{The Corpse Washer}

It is a novel written by the Iraqi novelist and poet Sinan Antoon in 2013. It talks about Young Jawad who is born in a traditional Shi'ite family that works in washing corpses in Al-Kadhimiya district in Baghdad. The conflict in the novel rises when Jawad wants to abandon the family work 
and become a sculptor which conveys the meaning that Jawad wants to celebrate life rather than living with death, and the refusal of his family to leave the family inheritance of being a corpse washer. The novel shifts between different tragic history events in Iraq like the war with Iran in 1980s, the gulf war in 1990s along with the economic sanctions at that time and lastly the 2003 invasion that unleashes the sectarian violence. The reader of the novel travels with Jawad in his tragic journey in which he transforms from an artist that appreciates life and represents it aesthetically into a person whose daily life is shaped by death, through the increasing number of corpses due to the increasing violence in the country. Yale University Press, Good Reads, Amazon, and others set a description to this novel as:

Through the struggles of a single
desperate family, Sinan Antoon's
novel shows us the heart of Iraqi's
complex and violent in recent
history. Descending into the hidden
meaning behind the text where the
borders between life and death are
blurred and where there is no refuge
form unending nightmares, Antoon
laments a world of great sorrow, a
world where the wind wail (Corpse
Washer, Yale University Press,
2014).

The novel sets out different themes: love, life and death, violence, sectarianism, war identity, and realism. Furthermore, the linkage between Jawad and the pomegranate tree, watered by the water that comes from washing corpses, is one of the main themes of the novel and sets a central metaphor in it. The comparison implements the relationship between life and death.

\section{Methodology}

The study adopts qualitative and quantitative research methods as assumptions will be supported by figures and tables to show the percentage and occurrence of character. In addition to this, the research claims are to be supported by using a corpus analysis program 'AntConc'; which is a freeware concordance program developed by Prof. Laurence Anthony. The program shows the concordance of a specific word. In other words, the program aims at showing a list of target words extracted from a given text or a set of texts. The use of this program will help the research to gain fast, reliable and authentic information about a specific word or a set of words in the novel, specially the occurrence of character`s names. Finally, all the results are to be interpreted from a critical perspective.

\subsection{Data Analysis}

All the selected texts are to be analysed according to the realisation mentioned in section 3 of this study. The study also includes a corpus analysis using one of the programs that are specialized in this concern (AntConc 3.5.8, 2019) to study the concordance of the SAs in the novel to give more validity and reliability to the analysis.

The study takes into consideration the way in which characters as SAs signal their own ideologies, and perspectives through their interaction. The current study tries to examine the topic through the major characters in the novel. These characters are Jawad, Jawad's Father, Jawad's mother, Reem, Ghayda', Ameer (Jawad's brother). Some examples from other characters are also examined to prove/ validate the hypotheses. The mechanism of the analysis depends on the interaction between Jawad and other characters through direct conversations due to the style of novel which is 'I-narration'. As a result, all possible hidden ideologies, and perspectives that socially construct the identity of the character and shape the way of interaction with society through the representation of others are to be investigated.

The current study focuses on the real actions happened in the novel without trying to analyse the nightmares that Jawad was facing due to the distortion within these actions and the anonymous SAs that appear in them. 
7 Exclusion and Inclusion in 'The Corpse

Washer'

\subsection{Exclusion}

\subsubsection{Suppression}

For the purpose of accurate analysis of suppression in the novel, the researcher divides the SA of suppression into six types depending on the way of its appearance in the novel:

1- Personal: the potential SA of this type is a person and the word 'by someone' can take place of the SA as in the examples below:

- A man: I told them I would take him and see that he was buried and pay for the whole thing. I signed the papers. (Chapter 42)

- Her bedroom was huge. The walls were white and the floor was covered with Persian carpets. (Chapter 14)

2- Impersonal: this type of suppression can be filled with 'by something'. It refers to the non-human $\mathrm{SA}$, as in the sentences below:

- I passed by the department of plastic arts. Its building was intact except for the windows. The glass had been shattered and the air conditioners removed from their metal racks. (Chapter 19)

- I walked to the library. The iron door had been unhinged and lay a few meters away. (Chapter 19)

3- Authoritative: in this type of suppression, the SA can be someone in an institution with authority on people, as in the following extract:

- Father was summoned to the directorate of secret police and was interrogated for three hours because of that one call. (Chapter 22)
- I was assigned to work at the Ministry of Health. (Chapter 29)

4- Situational: it deals with the suppression which occurs because of a specific situation that causes the action. The SA can be replaced by 'by the situation' as in the following examples:

- I asked him to call me should he need anything. He was surprised and asked me, "Don't you want to stay?" (Chapter 18)

- Most people were drained, and the fatigue was clearly drawn on their faces. (Chapter 52)

5- Societal: this type includes passive agent deletion that carries the meaning of the society as the SA, where 'by the society' can be an alternative to the $\mathrm{SA}$, as in:

- I, too, had to get my parents' approval, especially since marrying a divorcee was frowned upon. (chapter 28)

6- Criminality: it represents a specific type of human 'criminals' which do actions contrary to or forbidden by criminal laws. It is possible to replace the SA by 'by criminals'. The examples below demonstrate this type of suppression:

- De Mello and many others were killed. A few days later, Muhammad Baqir al-Hakim was assassinated. (chapter 26)

- Professor al-Janabi called to tell me that one of my colleagues from the academy, Adil Mhaybis, had been killed in the attack. (Chapter 48)

The table below shows the occurrences of the six types of suppression in the novel

Table (4-1) types of suppression

\begin{tabular}{||l||l||}
\hline Type of suppression & $\begin{array}{l}\text { Number } \\
\text { occurrences }\end{array}$ \\
\hline Personal & 84 \\
\hline Impersonal & 17 \\
\hline
\end{tabular}




\begin{tabular}{||l||l||}
\hline Authoritative & 40 \\
\hline Situational & 21 \\
\hline Societal & 1 \\
\hline Criminality & 27 \\
\hline Total & 191 \\
\hline
\end{tabular}

\subsubsection{Backgrounding}

Backgrounding is confined to adding some suspense to the presentation of characters as in chapter eight in the presentation Mr. Raid; the new art teacher. Jawad did the same thing in chapter twenty-four when he presented al-Fartusi for the first time as stated below.

- Jawad: He was in his late forties and short. His gray beard was neatly trimmed and edged with white. He wore round glasses with a silver frame. The bridge of his big nose left a space between his honey-colored eyes. The eyes sat under thick salt-andpepper eyebrows. He was wearing a flowing black robe and $a$ white turban. After greeting me, he extended his hand and offered his condolences. "May you have a long life, son. I am Sayyid
Jamal al-Fartusi. Forgive me, but I heard only yesterday."

\section{(Chapter 24)}

\subsection{Inclusion}

\subsubsection{Activation}

Due to the characteristics of the novel, the characters are included more than excluded and activated more than passivated. The features of first-person perspective narration novel that bound to a specific type of character representation in the novel are associated with the relation between the main character 'Jawad' and the other characters.

It is worth mentioning that it is hard to identify the aims, motives and ideologies of the SAs clearly because all the activities in the novel are seen through the eyes of the narrator 'Jawad'. However, Jawad tries to describe each character in a specific way so that the reader is able to draw an image to their personalities.

The current novel deals with two types of characters, the first one is real characters which they are real people of life and synthetic characters which are represented as real such as 'death'. Additionally, the novel tries to build an environment that is similar to the Iraqi society through the different representations of the characters that hold different ideologies and perspectives. The following table and figure demonstrate the representations of the main characters in the novel in terms of activation.

Table (4-2) The inclusions of the SAs in the novel

\begin{tabular}{|c|c|c|c|c|c|c|c|}
\hline \multirow[t]{2}{*}{ Character } & \multicolumn{3}{|c|}{ Direct mentioning } & \multirow{2}{*}{\begin{tabular}{|l}
$\begin{array}{l}\text { Circumstant- } \\
\text { ialization }\end{array}$ \\
By
\end{tabular}} & \multirow{2}{*}{$\begin{array}{l}\text { Possessive } \\
\text { pronoun }\end{array}$} & \multirow{2}{*}{\begin{tabular}{|l}
$\begin{array}{l}\text { Post } \\
\text { modification }\end{array}$ \\
Of
\end{tabular}} & \multirow[t]{2}{*}{ Total } \\
\hline & Name & Pronoun & $\begin{array}{l}\text { Relational } \\
\text { Identificati } \\
\text { on }\end{array}$ & & & & \\
\hline \begin{tabular}{|l|l} 
Jawad \\
\end{tabular} & 31 & 1722 & 17 & 5 & 25 & 33 & 1833 \\
\hline Father & 1 & 158 & 102 & 3 & 4 & 16 & 284 \\
\hline Reem & 41 & 198 & - & 1 & 8 & 13 & 261 \\
\hline Sabri & 13 & 172 & 22 & - & - & 2 & 209 \\
\hline Mother & - & 106 & 50 & 1 & 4 & 2 & 163 \\
\hline Ghayda' & 16 & 97 & - & 2 & 15 & 5 & 135 \\
\hline
\end{tabular}




\begin{tabular}{|c|c|c|c|c|c|c|c|}
\hline Hammoudy & 82 & 38 & - & - & 4 & 1 & 125 \\
\hline al-Fartusi & 5 & 110 & - & - & - & 1 & 115 \\
\hline Mahdi & 38 & 26 & - & - & - & 2 & 66 \\
\hline Ameer & 33 & 18 & 4 & - & - & 2 & 55 \\
\hline al-Janabi & 10 & 39 & - & - & - & 3 & 52 \\
\hline Death & 20 & 12 & & 3 & - & 12 & 47 \\
\hline Um Ghayda' & 9 & 2 & - & 1 & 1 & 1 & 15 \\
\hline 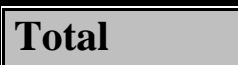 & 299 & 22698 & 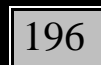 & $\sqrt{16}$ & 61 & 93 & 3356 \\
\hline
\end{tabular}

The table and the figure show the dominance of the representation of the main character 'Jawad' especially in terms of the pronoun representation 'I' with 1833 active representation in the novel. The table also shows the characteristics of the active representation of the other characters and their relations to the main character. Although the major conflicts between Jawad and his father is clear in the novel, but the father has the second largest representation in novel even with his death in chapter eighteen. The third largest representation is Reem, Jawad's lover which he remembers her often in the novel even with her disappearance in chapter twenty-eight. The fourth representation is Jawad's uncle 'Sabri' which represents the new ideology in post-war Iraq. The fifth character is Jawad's mother, with only 163 active representations even with her presence in the whole novel unlike the other characters.

The sixth is Ghayda', the other woman in Jawad's life, as she is presented 135 times. The seventh character is Jawad's father assistant Hammoudy. His active presentation in the novel was only 125 and his role is diminished after his disappearance in chapter twenty-seven and is replaced by another character 'Madi' which has $2 \%$ of the representation. The eighth character is al-Fartusi with $3 \%$ of the whole representation.

The ninth character is Jawad's brother, the person that supports the main character in his views and ideas. The active representation of Ameer's character is only 66 representations in the novel. The tenth is professor Islam Al-Janabi that has 52 representations. The eleventh character is Death. Ghayda' mother has the lowest representation in the table with less than $1 \%$.

\subsubsection{Passivation}

With regard to the way of SARs, it is represented to undergo the action of another doer rather than performing the action.

\section{Table (4-3) Passivation occurrence of the SAs}

\begin{tabular}{||l||l||}
\hline Character & Passivation \\
\hline \hline Jawad & 1031 \\
\hline Father & 228 \\
\hline Reem & 182 \\
\hline Mother & 91 \\
\hline Ghayda' & 73 \\
\hline Sabri & 72 \\
\hline al-Fartusi & 27 \\
\hline Ameer & 26 \\
\hline Hammoudy & 25 \\
\hline Mahdi & 16 \\
\hline al-Janabi & 11 \\
\hline Death & 1 \\
\hline Um Ghayda' & $\mathbf{1 7 8 7}$ \\
\hline \hline Total
\end{tabular}

Similar to activation, passive SAR shows Jawad's representation as the highest between the other characters with $55 \%$ as a recipient of the action. The percentages show Jawad's dominance as a SA_in this novel with 2868 representations in activation and passivation SA. 
All the other representations look similar to the representation to table (4-2) with some reduction in some characters to imply the meaning that some characters equally 'do' and 'receive' the action in the same manners.

It is important to mention that Death has been mentioned only one time. The occurrence of death as passivation is stated below:

- Mr. Ismail: He said that art was intimately linked with immortality: a challenge to death and time, a celebration of life. (Chapter 8)

\section{Discussion}

This part of the paper discusses the results that are presented earlier. The way of representation and the times of occurrence shows the impact of every SA on the storyline. Graph (1) shows the percentage occurrence of the main character in the novel.

\section{Graph (1) percentages of the inclusion occurrence of the SA}

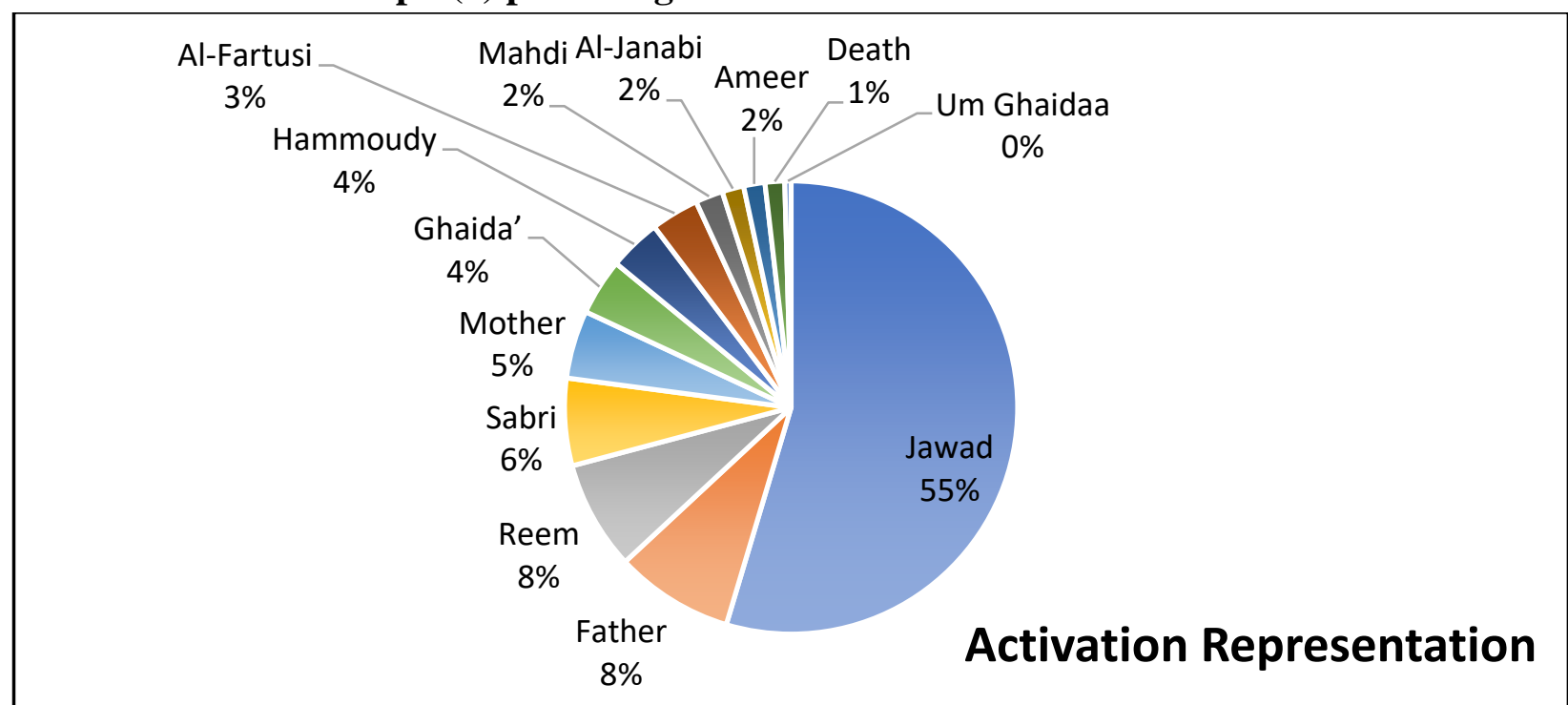

The graph clearly shows the effect of the father as it is evidence for the strong relationship between the two SAs and the major impact of his father on the personality of Jawad. The graph also demonstrates Reem's importance in the novel with $8 \%$ of occurrence. During the time of their relationship, Jawad reaches into the peak of his happiness but it decreases after her disappearance. Both of the characters "Reem and His Father" are permanent throughout the novel after their absence from the actions of in the novel.

The fourth SA is 'Sabri'. This character is present mainly in chapter twenty-one and with a small representation in further chapters but he has a strong relationship with Jawad which can be demonstrated through the large representation in the novel. The fifth SA is Jawad's mother with only $5 \%$. This can testify the minor effect of her character in the actions.

The sixth SA is Ghayda' as she records only in $4 \%$ compared to the other characters. The comparison between Reem and Ghayda' can clearly reveal Reem's major impact on Jawad's life more than Ghayda'. Ghayda' is a temporal character that is presented at chapter thirty-seven with no previous mentioning or impact on Jawad's life. Her mother has the lowest representation in the table with less than $1 \%$ due to the limited active role in the novel and the similarity in the ideology with Jawad's mother. Hammoudy is the version of the character that Jawad's father wants Jawad to be like. He is just like a third son to the family. He has $4 \%$ of active occurrence in the novel. 
The similarity between the devastation of Jawad and al-Fartusi is high. As both of them have witnessed unimaginable pain through their life, readers might predict that al-Fartusi is Jawad's future image which will be like him. Ameer's death seems to impact Jawad's personality but he somewhat gets over it as the active representation of Ameer's character is only $2 \%$ of the whole representation in the novel.

Professor Islam al-Janabi is the future person that Jawad looks forward to be like as the artist inside Jawad finds mutual ideas with this character. Jawad has met al-Janabi in his peak and has encouraged Jawad to be the man who always wanted to be. By the way contrast, all the events have forced Jawad to be someone else but himself. At this moment, the representation of al-Janabi is decreased.

Death with its different nature as a concept and not an actual human being is the key player of all the actions. Death in this novel has shaped all of Jawad's fate and personality. The representation of the death as a SA can confirm this idea.

The novel also has a considerable amount of passive SAR which has $35 \%$ of the total amount of the representations. The graphs below show the comparison between active and passive representation.

\section{Graph (2) percentages of activation and the passivation in the novel}

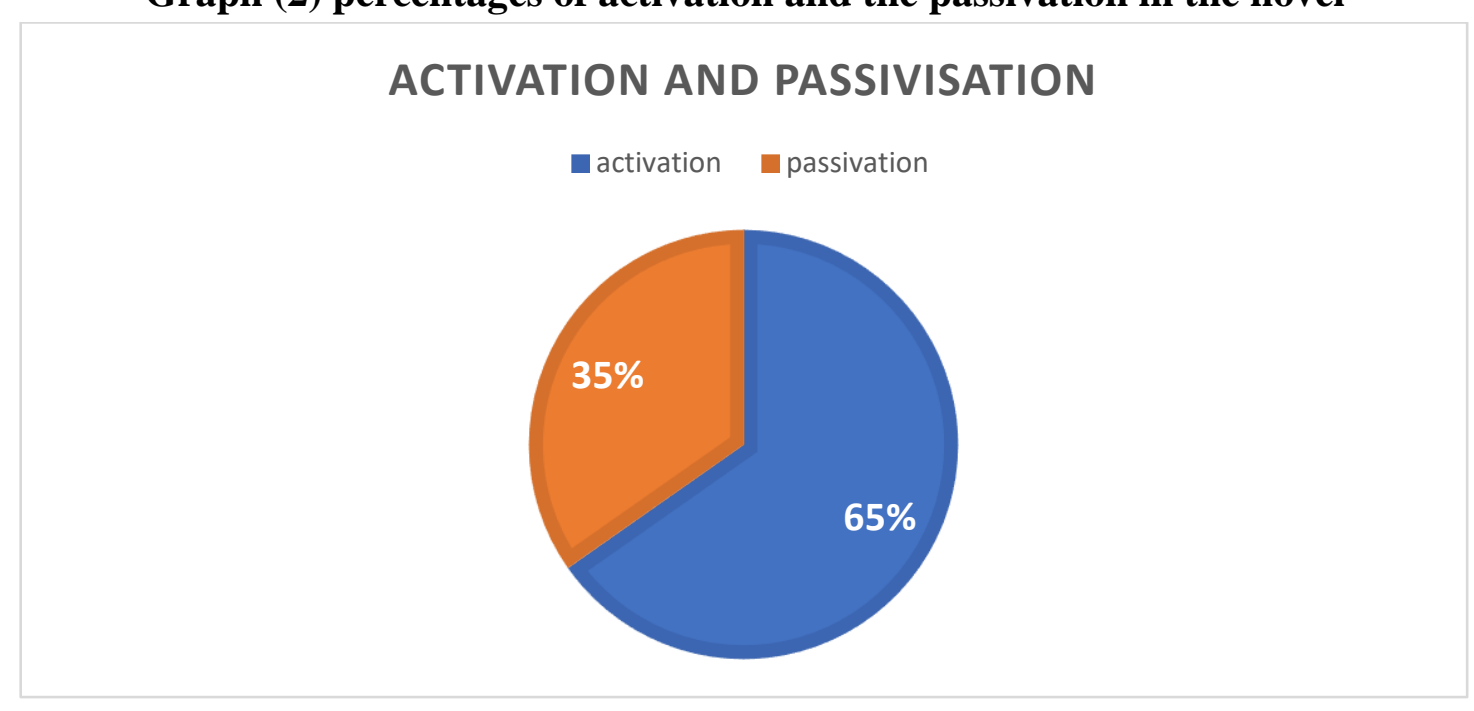

\section{Comparison of Characters using SAR}

Characters importance and effectiveness in the novel can be determined through the number of interaction and representation throughout the novel. In this section, the major characters in the novel with similar functions are analysed using
SAR to compare their roles and impact on the plot and the protagonist (Jawad). The selected characters are Jawad's parents (Father and mother) and Jawad's lovers (Reem and Ghayda')

9.1 Jawad's Father and Mother

\section{Graph (3) Comparison of (Father and mother)}




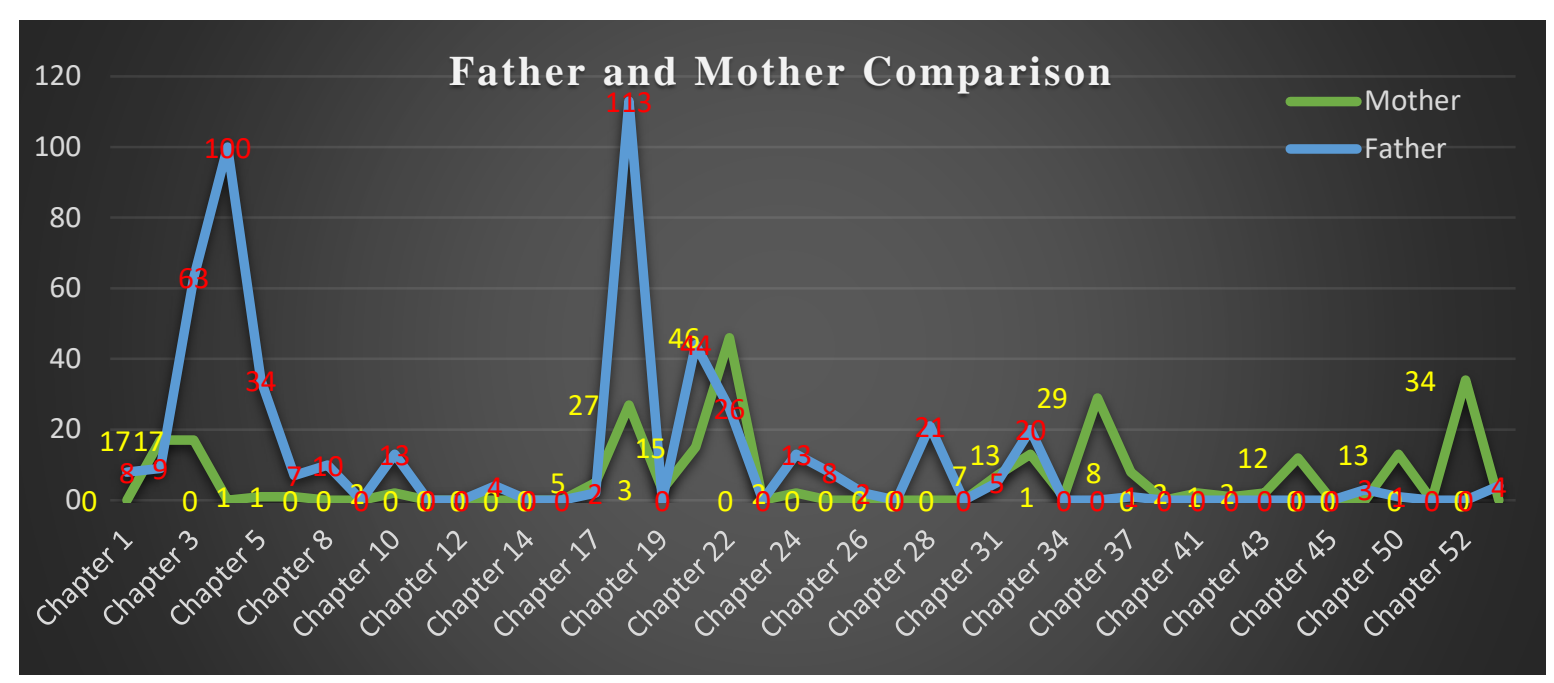

Graph (3) shows the major difference in the representaion between the two characters. Although Jawad's mother is present throughout the whole novel, but her representation is not as afficient as Jawad's father. Even with Jawad's Father death in chapter 18, the gragh clearly shows the impact of Jawad's father on the plot 512 representation. Also the highest representatio is 113 in one chapter. On the other hand, Jawad's mother has only 254 in the whole chapters representasion, while the highest representaion is 460 in chapter 22 . The comparison between these two characters show the the Father's influence on both the plot and Jawad's personality.

\subsection{Reem and Ghayda' (Jawad's lovers)}

\section{Graph (4) Comparison of (Reem and Ghayda')}

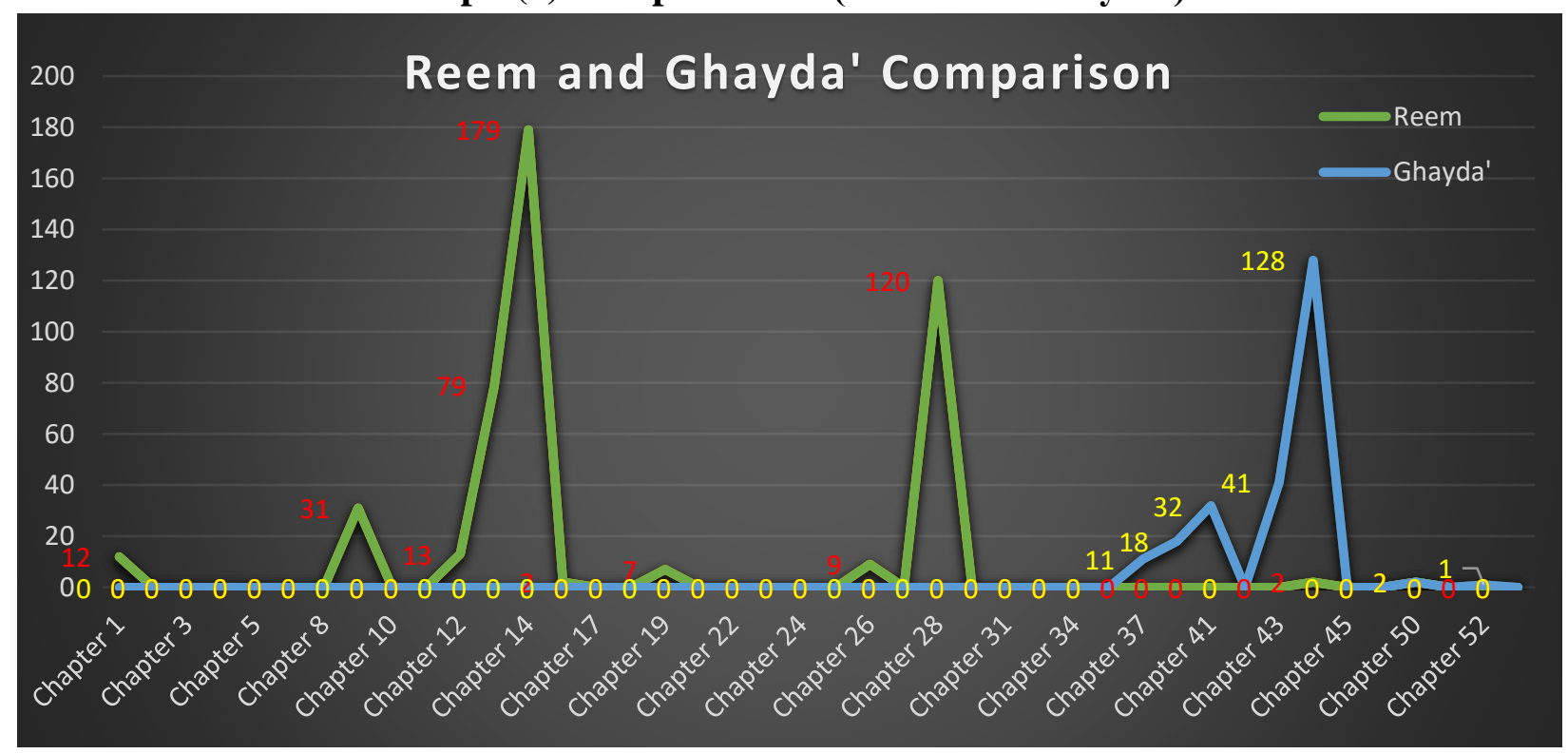

Graph (4) is a comparison between Jawad's lovers in the novel. Both of the characters have the same role in the novel but with one major difference which is the affect of each one on Jawad's personality. Firstly, Reem, she appears for the first time in Chapter 8 and she disappears suddenly in chapter 28. However, Reem has been mentioned before here actual appearance in chapter 1 and also after her disappearance as she was represented in chapter 43. Reem's Highest representation is in chapter 14 with 179 one and total representation of 443, while Ghayda' has not been mentioned before her actual appearance in chapter 37. Also, her highest representation was 
only 128 in chapter 44 with a total representation of 281 which is nearly half of Reem's representation in the whole novel. These results demonstrate that the influence in the plot of the novel and on Jawad's personality.

\section{Conclusions}

1. The study has arrived at a better understanding of the SAs in literary texts, providing a basis for the analysis of the literary text using a CDA model (SAR), in a more extended and effective way. Moreover, the study has shown a clear-cut positive effect of the use of the adopted model of analysis in collecting important information about the use of SAR in literary texts. It also confirms the previous studies by adding extra evidence that SAR can also study flexibly first-person narration novels.

2. The type of the novel, which is first-person narration, displays some difficulties in analysing its data due to the single reality and the focus on one character only. Nevertheless, the selected model is greatly workable in application.

3. In addition to CDA studies on literary works, the study has provided conclusive support for bridging the gap between the linguistic, the psychological, and literary parts. SAR has shown its ability to study factual data as well as the factual one.

4. The use of the program (AntConc 3.58) shows its effectiveness in collecting the data from the novel for the analysis. The program is used especially with quantitative analysis. It shows an accurate resent in a short time.

5. The quantitative analysis clearly shows the writer's intention, through Jawad's perspective, to pay attention to each character as a separate entity through the domination of the individualization in SAR. Moreover, the statistics show the use of active representation to SA in the novel more than passive representation and also inclusion more than exclusion. Notably, the novel employs a specific use to the generalization of SA by referring to a group of SAs or another social group.

\section{References}

[1] Antoon, Sinan. (2014). The Corpse Washer. London: Yale University Press.

[2] Anwar, Ifa Amalia. (2018) Social actor represented by President Donald Trump on Twitter. Undergraduate thesis, Universitas Islam Negeri Maulana Malik Ibrahim. http://etheses.uin-malang.ac.id/13204/ (Retrieved on 12 January, 2020)

[3] Babaii, Esmat and Rashed, Maliheh. (2017). 'Representation of social actors in Chinua Achebe's novel "Things fall apart" and its two Persian translations'. The International Journal for Translation \&Interpreting Research, 9 (3):151-165.

[4] Bernstein, Basil. (1990). The Structuring of Pedagogic Discourse. London: Routledge.

[5] Cook, Ellen. (1990). 'Gender and Psychological Distress'. Journal of Counseling \& Development, 68 (4):371375.

[6] De Beaugrande, Robert and Dressler, Wolfgang. (1981). Introduction to text linguistics (Vol. 1). London: Longman.

[7] Evayani, Widya. and Rido, Akhyar. (2019). 'Representation of Social Actors in Sexual Violence Issue in The New York Times and The Jakarta Post Newspapers: A Critical Discourse Analysis'. Teknosastik, 17 (2):43-55.

[8] Fairclough, Norman and Wodak, Ruth. (1997). 'Critical Discourse Analysis'. In Teun Van Dijk (ed.), Discourse as Social Interaction: Discourse Studies A Multidisciplinary Introduction, 258-284. London: Sage.

[9] Fairclough, Norman. (1993). 'Critical discourse analysis and the marketization of public discourse: the universities'. Discourse and Society, 4 (2):133-168 
[10] Foucault, Michel and Sheridan, Alan. (1972). The Archaeology of Knowledge. New York: Pantheon Books.

[11] Hall, Stuart. (1992). 'The West and the rest: Discourse and power'. In Formations of Modernity, 275-331. Polity Press in Association with the Open University.

[12] Joodi, Hussein. (2018). Characters as Social Constructs in G.B. Shaw's Man and Superman. Unpublished MA Thesis, University of Basrah, Basrah, Iraq.

[13] Paltridge, Brian. (2012). Discourse Analysis an Introduction (2nd ed.). London: Bloomsbury.

[14] Schiffrin, Deborah. (1994). Approaches to Discourse. Oxford: Blackwell.

[15] Stephens, John. (1992). Language and Ideology in Children's Fiction. London: Longman.

[16] Sunderland, Jane. (2004). Gendered Discourses. Basingstoke: Palgrave Macmillan.

[17] Talbot, Mary (1995) Fictions at Work: Language and Social Practice in Fiction. London: Longman.

[18] Van Dijk, Teun. (1988). News as Discourse. New Jersey: Lawrence Erlbaum Associates, Inc.

[19] Van Leeuwen, Theo. (2008). Discourse and Practice: New Tools for Critical Discourse Analysis. Oxford: Oxford University Press.

[20] Wodak, Ruth and Meyer, Michael. (Eds.). (2009). Methods for Critical Discourse Analysis (2nd ed.). London: Sage Publications.

\section{Endnote}

*This article is extracted from an MA thesis entitled Social Actors in Sinan Antoon's 'The Corpse Washer: A Critical Discourse Analysis, prepared by Ali Muhammed Ridha Abdulwahid and supervised by Asst. Prof. Dr. Raed Dakhil Kareem, The University of Kufa 2020 